\title{
Tindak Verbal Abuse dalam Permainan Mobile Legend di Indonesia: Kajian Sosiolinguistik
}

\author{
Muhammad Rais Almajid \\ Tadris Bahasa Indonesia, Fakultas Adab dan Bahasa \\ IAIN Surakarta \\ Raizal.Majid@gmail.com
}

\begin{abstract}
Mobile Legend is a game that is widely played by various groups from young to old. In communication, this game has provided a forum for communication in the form of chat or voice. But there are many found misuse of this communication space. Like players who often throw harsh words in the form of taunts / verbal swearings. The curses made by these fellow mobile legend players are of various types. The existence of this research is intended to find out how many types of verbal swearings are often spoken by mobile legend players in Indonesia. This study uses descriptive qualitative method, namely by collecting, analyzing and identifying verbal swear data. From this study found various types of verbal swearing which are classified into seven based on (1) animals, (2) professions, (3) limbs, (4) traits, (5) circumstances, (6) verbs, and (7) words object. The cursing cast by the player resulted in a decrease in the player's confidence in playing the Mobile Legend game well and caused the anger of the player who was hurled by hurtful swearings.
\end{abstract}

Keywords: Verbal abuse, sociolinguistics

\begin{abstract}
Abstrak
Mobile Legend merupakan permainan yang banyak dimainkan oleh berbagai golongan dari muda hingga tua. Dalam bermunikasi, permainan ini telah menyediakan wadah berkomunikasi dalam bentuk chat atau suara. Namun banyak sekali ditemukan penyalahgunaan ruang komunikasi ini. Seperti pemain yang sering melontarkan kata-kata kasar berupa ejekan berupa/ umpatan verbal. Umpatanumpatan yang dilontarkan oleh sesama pemain mobile legend ini berbagai macam jenisnya. Dengan adanya penilitian ini ditunjukan untuk mengetahui seberapa banyak jenis umpatan verbal yang sering diucapkan oleh para pemain mobile legend di Indonesia. Penelitian ini menggunkan metode kualitatif deskriptif yaitu dengan mengumpulkan, menganalisis serta mengindentifikasi data umpatan verbal. Dari penelitian ini ditemukan berbagai jenis umpatan verbal yang digolongkan menjadi tujuh berdasarkan (1) hewan, (2) profesi, (3) anggota tubuh, (4) sifat, (5) keadaan, (6) kata kerja, serta (7) kata benda. Umpatan-umpatan yang dilontarkan pemain mengakibatkan penurunan kepercayan pemain dalam memainkan game Mobile Legend dengan baik serta mengkibatkan kemarahan pemain yang dilontari umpatan-umpatan yang menyakitkan hati.
\end{abstract}

Kata kunci: Penyalahgunaan verbal, sosiolinguistik 


\section{Pendahuluan}

Baru-baru ini para gamers digemparkan dengan rilisnya permainan baru yang bernama Mobile Legend. Mobile Legend merupakan salah satu permainan yang dilakukan secara tim dengan tujuan mengahancurkan menara (tower) yang dimiliki tim lawan. Satu tim terdiri atas lima orang dan setiap masing-masing orang berhak memainkan satu hero. Di dalam permainan ini terdapat map yang terbagi menjadi tiga jalur yaitu tengah, atas, dan bawah. Masing-masing bagian jalur terdiri atas tiga menara (tower). Hingga sekarang, permainanan online ini sangat digandrungi oleh berbagai golongan orang di dunia.

Permainan ini telah dirilis pada 24 September 2016. Permainan ini sudah diunduh lebih dari 100 juta pengguna di dunia. Lomba-lombapun sudah banyak diadakan oleh berbagai komunitas di Indonesia dan internasional. Pemerintahpun juga mengadakan perlombaaan piala presiden untuk gemers. Hadiah yang dihasilakan juga fantastis hingga beratus juta. Hal ini salah satu sebab semakin banyaknya peminat Mobile Legend. Berbagai tanggapan banyak muncul mengenai permainan ini yang menyamakan dengan permainan Dota 2. Hanya saja perbedaanya terdapat dalam pengaplikasian game. Untuk Dota 2 belum bisa dimainkan dalam ponsel berbeda dengan mobile legnd yang sudah bisa dimainkan dalam ponsel ataupun komputer.

Fitur-fitur yang disajikan antara dota 2 dan mobile legend masih sama tidak berbeda jauh. Salah satunya adalah fitur komuniasi. Saat sedang permainan berlangsung atau sedang menentukan formasi sebelum melakukkan permainan para tim akan mendiskusikan teknik atau cara menyerang dengan menggunakan fitur komunikasi yang sudah disediakan oleh pihak pengembang permainan tersebut. Fitur komunikasi ini terdapat dua pilihan komunikasi. Secara lisan atau tulis. Tim ini dibuat dengan cara acak oleh pihak ketiga. Saat melakukan diskusi para pemain sering sekali menggunakan bahasa daerah mereka hingga kadang terjadi kekeliruan dalam pemaknaan ucapan atau tulisan yang mereka sampaikan ke setimnya.

Peran bahasa yang sama sangat diperlukan untuk mencapai pemahaman yang sama. Salah satunya dengan komunikasi bahasa Indonesia. Pada dasarnya bahasa merupakan salah satu sarana alat komunikasi berupa simbol bunyi yang dihasilkan oleh alat ucap manusia. Bahasa juga menjadi instrumen penting dalam komunikasi sehingga tanpa bahasa manusia akan kesulitan untuk menyampaikan pendapat, gagasan, maupun ide yang mereka pikirkan. Dalam kehidupan, kita menggunakan bahasa untuk berpikir, menyimak, berbicara, membaca, dan menulis. 
Bahasa adalah sistem simbol bunyi yang bermakna dan berartikulasi (dihasilkan oleh alat ucap) yang bersifat arbitrer dan konvensional, yang dipakai sebagai alat komunikasi oleh sekelompok manusia untuk melahirkann Bahasa merupakan sebuah alat yang digunakan dalam berkomunikasi secara tulis atau lisan yang dapat dipahami antara penutur dan yang diberi tuturan. Dengan bahasa para pemain dapat berdiskusi dan membuat strategi dalam menentukan cara bermain Mobile Legend. Bahasa tulis adalah komunikasi yang dilakukan dengan perantara tulisan tanpa adanya pembicaraan secara langsung, dengan menggunakan bahasa yang singkat, jelas dan dapat dimengerti oleh penerima. Hal tersebut sesuai dengan pernyataan Kentjonom dalam (Oktaviani. 2018) bahwa ada tiga fungsi utama bahasa, yaitu sebagai alat kerja sama, berkomunikasi, dan mengidentifikasi diri.

Namun mirisnya permainan Mobile Legend ini telah menyebabkan pemain sering melakukan tindakan kekerasan verbal kepada satu timnya atau lawanya berupa umpatan. Tindakan verbal abuse atau umpatan merupakan kekerasan yang dilakukan oleh pihak penutur kepada orang yang diberi tuturan dengan sebuah kata atau kalimat yang kasar berupa mencela, menghina, dan merendahkan. Menurut Sutikno dalam (Putri et al. 2012) Kekerasan verbal adalah kekerasan secara lisan atau tulisan terhadap perasaan orang lain menggunakan kata-kata yang kasar tanpa menyentuh fisiknya. Kata-kata yang memfitnah, kata-kata yang mengancam, menakutkan, menghina, atau membesarbesarkan kesalahan orang lain. Kekerasan verbal merupakan tindakan berupa penghinaan, pelecehan, dan memberi label seseorang dalam suatu pola komunikasi. (Huraerah 2012) mengatakan bahwa kekerasan verbal adalah tindakan yang dilakukan dalam bentuk memarahi, memaki, dan mengomel secara berlebihan dengan mengeluarkan kata kasar kepada orang lain. Hal ini seakan-akan meyebabkan orang yang dihina akan merasa terganggu secara emosional. Dampak buruk akan terjadi pada penutur ataupun yang diberi tuturan menjadikan kebiasaan pegucapan kata kasar dalam aktivitas sehari-hari.

Penelitian terkait kekerasan verbal terhadap game online juga pernah dilakukan oleh (Fariz 2017) dalam judul: jurnal komunikasi trashtalk dalam permainan game online dota 2. Dalam penelitian ini trashtalk atau ucapan kotor merupakan tindakan yang tidak baik bagi para pemain game atau yang lainya. Jika sering terbiasa menggunakan kata yang kasar dan kotor baik dalam dunia gamers, sosial media biasanya sering akan menimbulkan kebiasan yang buruk. Sehingga kebiasaan buruk ini berdampak kepada orang yang diberi ucapan dan pemberi ucapan berupa peremehan, sanksi sosial, emosional, dan menimbulkan konflik. Penelitian ini merupakan penelitian yang mengandung kebaruan karena dilakukan dalam permainan Mobile Legend yang belum 
ditemukan peneliti yang meneliti dan hingga sekarang masih banyak yang memainkan dari anak kecil hingga dewasa.

Kajian sosiolinguistik baik digunakan karena berhubungan dengan efek yang timbul dari kegiatan kekerasan verbal. Sosiolinguistik sendiri merupakan ilmu yang memperlajari tentang bahasa-bahasa yang diucap secara lisan atau tulisan dengan mengkaji penggunaan bahasa dalam kelas sosial masyarakat (Rijal, 2015). Meyerhoff mengatakan bahwa sosiolinguistik digunakan sebagai langkah awal untuk menganalisis struktur bahasa dalam penggunaanya dan sikap bahasa yang digunakan. Beberapa kajian sosiolinguistik hanya dapat meninjau sistematis melalui pemerikasaan rekaman dan pemahaman yang baik melalui latar belakang komunitas (Kurniasih 2017).

\section{METODE PENELITIAN}

Penelitian ini dikategorikan ke dalam penelitian kualititif deskriptif. Metode pendekatan deskriptif kualitatif adalah metode pengolahan data dengan cara menganalisa faktor-faktor yang berkaitan dengan objek penelitian dengan penyajian data secara lebih mendalam terhadap objek penelitian (Aan Prabowo, Heriyanto, S.Sos. 2013). Penelitian yang memberikan gambaran secara detail mengenai sesuatu permasalahan berdasarkan data yang ada, untuk dianalisiss diidentifikasi dan mengambil data-data verbal abuse yang diucapkan secara lisan atau tulisan oleh para pemain di dalam permaianan Mobile legend (Jaya, 2016). Ada beberapa langkah yang dilakukan dalam melaksanakan penelitian tersebut dengan mencari data, mengelola data, dan menyajikan data yang ada. Pada proses pencarian data, peneliti mengunakan metode memotret, menulis, dan mengamati.

Dengan adanya penelitian ini diharapkan akan dapat mengidentifikasi dan mengklasifikasikan berbagai banyak jenis kata umpatan yang sering digunakan untuk melecehkan atau menghina teman satu tim atau lawan secara lisan dan tulisan pada saat bermain Mobile Legend. Serta mengetahui sebab penyebab menutur mengucapkan umpatan serta mengetahui dampak sosial bagi yang diberi tuturan dalam kehidupan sosialnya dengan teman sebayanya.

\section{PEMBAHASAN}

Berdasarkan hasil penelitian mengenai kekerasan verbal yang terdapat pada permainan Mobile Legend menunjukan bawasanya banyak variasi-variasi kata yang digunakan untuk mengumpat lawan main. Menurut (Winiasih 2010) umpatan merupakan ungkapan spontan yang berupa kata kasar sebagai curahan hati penutur menujukan fungsi emotif berdasarkan fungsi bahasa yang dipaparkan Jakobson. 
Umpatan yang keluarkanpun bervariasi. Wijaya dalam (Triadi 2017) mengatakan bawasanya umpatan/makian dalam bahasa indonesia dapat digolongkan menjadi berbagai macam: (1) keadaan, (2) binatang, (3) benda-benda, (4) bagian tubuh, (5) kekerabtan, (6) mahluk halus, (7) kotoran manusia dan binantang, (7) keadaan orang, (8) profesi, (9) seruan. Dari jenis umpatan yang disebutkan oleh Putu Wijaya dalam permainan Mobile Lagend ditemukan terdapat beberapa jenis umpatan seperti umpatan menghewankan "anjing lo", umpatan bagian tubuh "kontol nyampah anjing", umpatan kata sifat "tolol", umpatan keadaan orang "evos botak kontol”, umpatan kotor "tai". Ini hanya beberapa kata yang sudah dipaparkan. Dari hasil peneltian ini terlihat jelas bahwa penggunaan bahasa umpatan yang terbanyak akan ditemukan dengan metode penelitian kuantitatif deskriptif.

\section{Bentuk umpatan yang ada pada permainan Mobile Legend.}

\section{Umpatan yang menggunakan kata hewan}

Hewan merupakan mahluk hidup yang tidak memiliki insting seperti manusia. Hewan juga merupakan mahluk hidup yang bebas. Namun, hewan dan manusia ada yang hidup berdampingan. Ada juga binatang yang memang hidup tidak berdampingan dengan manusia karena alasan dilarang oleh agama dan tidak baik untuk kesehatan. Dari sifat hewan-hewan yang negatif ini banyak sekali manusia dan para pemain Mobile Legend menggunakan nama hewan sebagai umpatan. Berikut ini jenis nama hewan yang sering disebut dalam permainan Mobile Legend:

\section{Anjing}

Kata "anjing" termasuk makna leksikal karena memiliki satu arti yaitu binatang menyusui yang bisa dipelihara untuk menjaga rumah, berburu (Jannah, Widayati, and Kusmiyati 2017). Dalam bahasa Jawa sendiri anjing berarti asu. Pemilihan anjing sebagai kata umpatan karena hewan ini merupakan hewan yang najis menurut agama islam. Dan ajing ini merupakan hewan yang memiliki sifat liar suka mengeluarkan air liur dan mengendus. Inilah kenapa manusia terispirasi untuk mengunakan hewan anjing sebagi umpatan.

Contoh: anjing ml ping jele

Dalam contoh tersebut terlihat bahwa anjing memilki arti umpatan yang negatif dari segi apapun. Dalam kalimat di atas menunjukan juga bahwa kata anjing juga memiripkan orang yang diberi umpatan terhadap hewan tersebut. Hal ini mengakibatkan emosi lawan karena diberi tuturan seperti itu. 


\section{Babi}

Babi merupakan hewan yang hidup secara beranak. Hewan ini merupakan hewan yang hidup di tempat yang berlumpur dan mau memakan apa saja yang ada termasuk kotoranya sendiri. Hewan ini memiliki sifat pemalas dan memilki besar nafsu. Hal itu yang menyebabkan manusia menggunakan nama Babi sebagai umpatan.

Contoh: babi najis amit-amit

Dalam contoh terlihat bahwa penutur mengungkapkan kalimat itu ke pemain lawan karena menyamakan pemain lawan seperti babi. Karena sifatnya yang bermain malas dan ingin enaknya saja.

\section{Umpatan yang menggunakan bagian tubuh manusia}

Anggota tubuh merupakan susunan yang struktur yang dibuat oleh tuhan secara sempurna. Dan semua anggota tubuh manusia itu memiliki cara kerja yang masingmasing berbeda. Namun, tidak semua bagian tubuh dapat disebutkan dengan umum. Hal ini membuat manusia menyebutkan yang tidak umum agar merasa malu.

\section{Kontol}

Kontol merupakan kata bahasa jawa yang dalam bahasa indonesia memiliki arti penis atau kemaluan laki-laki. Kata ini merupakan umpatan yang paling kasar kerena menyinggung anggota tubuh yang secara umum tidak seharusnya disebutkan oleh penutur secara umum.

Contoh: kontol nyampah

Dalam contoh terlihat bahwa penutur sengaja mengucapkan kata "kontol" agar pemain lawan merasa malu karena kalah atau menyadarkan karena satu timnya yang berbuat salah.

\section{Memek}

Memek merupakan kata yang memilki arti kemaluan perempuan atau vagina. Kata ini juga merupakan kata yang umum disebutkan dimuka umum. Para manusia menggunakan umpatan kata memek ini untuk membuat malu dan memancing emosi lawan.

Contoh: memek cuk!! 
Pada kata yang berada di atas menunjukan bahwa kata "memek" bermaksud untuk menyinggung lawan dan memiripkan lawan seperti perempuan. Dan untuk satu timnya untuk menyadarkan bahwa timnya bukan perempuan tapi memiliki sifat sebagai seorang lelaki.

\section{Umpatan yang menggunakan kata sifat}

Kata sifat merupakan kata yang menunjukan watak atau gambaran mengenai seseorang atau benda secara lahiriah. Kata ini diambil oleh manusia yang negatik saja untuk dijadikan sebuah umpatan yang dapat menyakitkan perasaan lawan.

\section{Goblok atau Tolol}

Goblok merupakan kata bahasa jawa yang dalam bahasa indonesia memiliki arti bodoh. Bodoh sendiri memiliki arti yang tidak lekas mengerti jika diberi informasi. bodoh merupakan contoh makian bentuk satuan monomorfemik berupa kata dasar dalam Melayu dialek Selimbau. Kata banga 'bodoh' merupakan morfem dasar yang bebas. Artinya, morfem tersebut tidak digabungkan dengan morfem lain seperti imbuhan, klitika, bentuk dasar yang lain, pemajemukan, atau pengulangan (Damayanti 2017). Hal ini alasan mengapa manusia sering menggunakan umpatan ini untuk ditunjukan kepada lawan pemainya.

Contoh: tolol luh semua goblok ign

Kalimat di atas jelas menunjukan bahwa sengaja mengucapkan kalimat itu karena merasa jengkel terhadap teman satu timnya yang sulit untuk memahami kreteria cara bermain yang baik.

\section{Umapatan yang menggunakan kata benda}

Kata benda merupakan kata yang menunjukan sebuah benda. Agar manusia bisa memahami dengan mudah semua jenis benda. Akan tetapi sekarang banyak manusia menjadikan kata benda sebagai umpatan yang tidak baik.

\section{Tahi}

Tai adalah kata yang tidak baku dari kata tahi. Tahi merupakan ungkapan dalam bahasa Mandarin yang berarti sedang buang air besar. Aktivitas ini dianggap memiliki nilai yang buruk di lingkungan (Masykur 1994). Tahi merupakan kotoran sisa metobolisme mahluk hidup yang keluar dari anus mahluk hidup. Tahi memiliki sifat 
benda yang menjijikan. Dengan itu manusia menjadikan tahi sebagai umpatan yang menggambarkan lawanya yang menjijikan karena cara bermainya.

Contoh: tai lo semua tolol

emang tai

Kalimat di atas menunjukan unsur kejelekan yang menyamakan orang dengan sebuah kotoran yang menjijikan. Dengan mengumpat seperti ini penutur berharap bahwa satu tim sadar atas kesalahan yang diperbuatnya.

\section{Umpatan dengan menggunakan kata kerja}

\section{Ngentot}

Ngentot merupakan bahasa Jawa dalam bahasa Indonesia memilki arti bersetubuh. Kata ini sangat kasar, karena tidak sepatutnya diucapkan di muka umum. Karena ngentot merupakan sebuah aktivitas yang dilakukan secara tertutup oleh suami istri. Dengan itu manusia sengaja menggunakan kata ngetot sebagai umpatan untuk membuat malu dan marah.

Contoh: ngentot ngentot

Di dalam kalimat tersebut penutur mengucapkan itu merasa jengkel karena pemain satu timnya yang tidak ingin menyerang tapi hanya berada di belakang untuk berjagajaga. Dengan mengucap kata tersebut berharap pemain satu timnya segera sadar atas kesalahanya.

\section{Bacot}

Bacot merupakan bentukan kata dari bahasa Jawa yang di dalam bahasa Indonesia memiliki arti ngomong. Bacot sendiri dikalangan umum dapat dikatakan sebagai sebutan orang yang kebanyakan berbicara. Hal ini dijadikan manusia sebagai umpatan untuk memberikan respon kepada orang yang banyak bicara namun tidak bertindak atau agar segara diam.

Contoh: bacot kontol jesno

Di dalam permainan mobile lagend para penutur sring mengucapkan kata umpatan itu karena merasa teman satu timnya hanya mengatur namun tidak segera bergerak untuk melawan musuh. Dengan mengumpat seperti itu diharapkan agar yang beri tuturan segera sadar atas kesalahnya. 


\section{Umpatan Keadaan Orang}

Umpatan keadaan orang merupakan umpatan di mana melihat keadaan orang yang akan diberi umpatan sesuia dengan keadaanya. Dengan para manusia sering menggunakan upmpatan tersebut untuk merendahkan orang lain.

\section{Botak}

Dalam bahasa kamus bahasa Indonesia botak merupakan keadaan di mana orang tidak memiliki rambut sama sekali. Hal ini dijadikan manusia sebagai umpatan untuk membuat malu yang diberi umpatan.

Contoh: evos botak

Dalam kata botak ini menunjukan untuk merendahkan orang tersebut, karena merasa kesal dengan cara mainya dan menunjukan kepada orang yang sesuai dengan keadaan orang yang diberi umpatan.

\section{Umpatan dengan Profesi}

Umpatan dengan sebutan profesi merupakan umpatan yang biasanya menjelekjelekan pekerjaan. dalam umpatan profesi menggunakan model yang mengacu pada profesi rendah atau yang dharamkan agama. Banyak dari manusia menggunaka profesi yang rendah untuk dijadikan umpatan karena status sosial ( Winiasih:2010 ).

\section{Bajingan}

Bajingan dalam kamus bahasa Indonesia memiliki arti sebagai pencuri atau pencopet. Bajingan ini merupakan profesi yang sangat dilarang agama dan profesi yang paling rendah karena merugikan sesama manusia. Bajindul, bajigur, bajingseng, bajingpret, dan bajinguk adalah pisuhan yang berasal dari kata bajingan. Sesuai dengan karakter masyarakat Mataram yang lembut, untuk memberi umpatan masyarakat ini tidak menggunakan ungkapan yang menunjukkan pisuhan tersebut secara langsung, namun dengan menyamarkannya dengan menambahkan kata atau mengganti sebagian dari ungkapan tersebut (Muktiono et al. 2013).

\section{Contoh: bajingan}

Pada kata ini pemain mengucapkan kata bajingan kerena mereka emosi terhadap satu timnya yang sering tiba-tiba datang saat lawan sudah mengalami kritis dan satu tim datang untuk membunuh. Akibatnya yang mendapatkan poin adalah yang membunuh 
tadi. Yang sudah berusaha dari awal tidak mendapatkan apa-apa. Hal ini diucapkan oleh pemain agar teman satu timnya sadar jika sudah melakukan kesalahan.

Ditinjau dari fungsinya jelas bawasanya umpatan kata kasar yang dikeluarkan oleh para pemain merupakan spotanitas karena merasa kesal dan tidak terima karena kekalahan. Menurut (winiasih,2010) umpatan merupakan ungkapan spontan yang berupa kata kasar sebagai curahan hati penutur menujukan fungsi emotif berdasarkan fungsi bahasa yang dipaparkan Jakobson.

\section{PENUTUP}

Kekerasan verbal sering terjadi dan diungkapkan oleh setiap individu yang merasa emosi ataupun mendapat hal negatif yang menimpa dirinya. Di antara yang sering diketemui oleh penulis dalam umpatan kekerasan verbal terjadi pada seseorang yang sedang bermain game. Salah satu game yang sedang trending adalah Mobile Legend. Demikian tedapat beberapa verbal kasar yang sering diungkapkan oleh pemain Mobile Legend. Ungkapan ini dilontarkan oleh pemain lantaran merasa emosi terhadap dirinya ataupun juga dilakukan oleh sesama tim dalam bermain lantaran sudah melakukan kesalahan yang mengakibatkan kekalahan saat bermain Mobile Legend. Di dalam umpatanya ditemukan banyak sekali berbag ai jenis umpatan yang sering diucapkan. Berbagai jenis umpatan ialah umpatan hewan, umpatan profesi, umpatan keadaan orang, umpatan organ tubuh, umpatan kata sifat, dan umpatan kata benda.

Ungkapan yang kasar sering sekali berakibat menyakiti perasaan orang. Banyak sekali jenis umpatan verbal yang dilakukan oleh para penggmar permainan Mobile Legend. Ungkapan tersebut banyak sekali mereka dapatkan dipercakapan saat bermain ataupun sedang berdiskusi dalam membuat taktik dalam bermain Mobile Legend. Diharapkan para pemain Mobile Legend tidak lagi mengungkapkan tindakan kekerasan verbal yang bisa mengakibatkan perasaat sakit hati atau membuat perkelahian antar sesama tim. Dengan adanya penelitian kecil ini diharapkan akan adanya penelitian lebih besar lagi mengenai permainan Mobile Legend dari segi bahasa ataupun yang lainya.

\section{DAFTAR PUSTAKA}

Aan Prabowo, Heriyanto. 2013. "Analisis Pemanfaatan Buku Elektronik (E-Book) Oleh Pemustaka Di Perpustakaan SMA Negeri 1 Semarang.” Jurnal Ilmu Perpustakaan 2 (2): 1-9. http://ejournal-s1.undip.ac.id/index.php/jip\%5C.Analisis

Apriani, Sarah. dkk. 2018. "Pengunaan Bahasa Indonesia Pada Diskusi Siswa SMA Negeri 4 
Surakarta: Kajian Dengan Prinsip Kerja Sama Grice Dan Relevansinya Sebagai Bahan Ajar Keteramian Berbicara. Universitas Sebelas Maret” 6 (1): 281-301.

Damayanti, Wahyu. 2017. "Makian Dalam Bahasa Melayu Dialek Selimbau Kapuas Hulu” 45 (1): $32-46$.

Fariz, Achmad. 2017. "Gamers Dalam Permainan Game Online Dota 2 Di Warung Internet Tumang Game Online Kabupaten Sukoharjo,” no. 16.

Huraerah, Abu. 2012. Kekerasan Terhadap Anak. Bandung: Nuansa Cendikia.

Jannah, Almaidatul, Wahyu Widayati, and Kusmiyati. 2017. "Bentuk Dan Makna Kata Makian Di Terminal Purabaya Surabaya Dalam Kajian Sosiolinguistik” 4 (2): 43-59.

Kurniasih, Dwi. 2017. "Satuan Ekspresi Pada Kemasan Botol AQUA.” Jurnal Bahasa Lingua Scientia 9 (2): 319-46.

Masykur, Purami Sarah Sita. 1994. "Bentuk Dan Fungsi Umpatan Oleh Siswa SMA Negeri 2 Manaje, Sulawesi Barat Dalam Situasi Non Formal” 2 (2): 63-75.

Muktiono, Dadung Ibnu, Dedi Irwanto, Muhammad Santun, Dhanang Respati Puguh, et al. 2013. "Apakah Pisuhan Selalu Bermakna Negatif ?: Fungsi Pisuhan Dalam Masyarakat Arek Dan Masyarakat Mataraman ( Are Swear Words Always Perceived Negatively ?: The Function of Swearing in Arek Society and Mataraman Society )" 13 (2): 165.

Oktaviani, Feny. 2018. "Analisis Kesalahan Berbahasa Indonesia Pada Karangan Eksposisi Siswa Kelas X Mipa Universitas Sebelas Maret Surel :” 6 (3): 94-109.

Putri, Annora Mentari, Agus Santoso. 2012. "Persepsi Orang Tua Tentang Kekerasan Verbal Pada Anak.” Jurnal Nursing Studies 1: 22-29.

Triadi, Rai Bagus. 2017. "Pegunaan Makian Bahasa Indonesia Pada Media Sosial (Kajian Sosiolinguistik)" 5: 1-26.

Winiasih, Tri. 2010. Kajian Sosiolinguistik Program Pascasarjana. Surakarta: Universitas Sebelas Maret. 
Estetik, Vol.2 No.2, November2019

ISSN 2622-1810 (p) 2622-1829 (e) 